\title{
A FORMAÇÃO CONTINUADA PARA OS PROFESSORES DE EDUCAÇÃO FÍSICA NO CONTEXTO DO PROJETO DE ACELERAÇÃO DA APRENDIZAGEM EM GOIÁS ${ }^{1}$
}

\author{
Wanderson Ferreira Alves ${ }^{2}$ \\ “[...] os professores são maus implantadores \\ das idéias dos outros." \\ (McDonald, apud Imbernón, 2000, p. 90)
}

\section{RESUMO}

O objetivo deste artigo é analisar a perspectiva de formação docente instituída para os professores pertencentes ao Projeto de Aceleração da Aprendizagem em Goiás, enfocando particularmente os professores de educação física. Para a realização deste trabalho foi utilizada a análise documental, referente ao próprio projeto do programa de aceleração de aprendizagem, bem como a reflexão teórica com autores que discutem o tema da formação de professores. O estudo permitiu perceber uma perspectiva de formação continuada marcada pela racionalidade técnica e pela desvalorização dos saberes dos docentes, revelando também uma concepção de educação física muito diferente da que vem sendo desenvolvida pelas instituições de ensino superior em Goiás.

Palavras-chave: educação física, formação continuada, ensino fundamental, aceleração da aprendizagem.

\footnotetext{
${ }^{1}$ Artigo recebido em 3/6/2003 e aprovado em 11/7/2003.

${ }^{2}$ Mestrando em Educação pela FE/UnB e bolsista da Capes. [e-mail: wandersonfalves@ yahoo.com.br]
} 


\section{INTRODUÇÃO}

O quadro das significativas mudanças que vem ocorrendo em nossa sociedade nas últimas décadas tem trazido em evidência a questão da educação e mobilizado até encontros internacionais na busca de uma agenda que avance no sentido de ampliação e melhora da prática educativa. Isso tem fomentado uma série de iniciativas em âmbito nacional e local.

No caso do estado de Goiás, uma dessas iniciativas foi um projeto para corrigir o problema da distorção entre idade e série dos alunos. O projeto "Aceleração de Aprendizagem de 5a e 6" séries", como assim foi chamado, exigiu para sua implementação um determinado tipo de formação do professor e, no caso da educação física, estabeleceu determinada concepção a partir da qual essa disciplina seria tratada no espaço escolar. Assim, o presente artigo tem como objetivo investigar as contradições inerentes à proposta de formação de professores do referido projeto e para isso faz uso da análise documental, referente ao projeto do programa de aceleração da aprendizagem, e da reflexão teórica com autores que discutem a formação de professores.

Nas últimas décadas, a palavra educação tornou-se fácil de ser encontrada nos discursos dos parlamentares, no clamor dos empresários e nos debates de organizações internacionais, como a Unesco e o Banco Mundial. Essas chamadas por um outro tipo de educação e por sua ampliação não são inocentes e precisam ser compreendidas dentro do atual contexto em que se estrutura nosso modo societal.

Durante décadas, com a estruturação do modelo taylorista e com o fordismo, o mundo da produção requereu um tipo de trabalhador especializado e bom conhecedor de sua atividade específica. $\mathrm{Na}$ atualidade, quando a produção é organizada não pelas rígidas formas anteriores, mas pela flexibilidade do tayotismo, esse tipo de trabalhador torna-se indesejável, passando-se a requerer um trabalhador que compreenda o processo e seja polivalente. ${ }^{3}$ Estamos, então, no mundo da globalização e dos apelos tecnológicos, ${ }^{4}$ e nele a educação passa a ser percebida como meio de adaptação das pessoas à nova realidade 
e o professor, como o agente da mudança. É no bojo dessas profundas transformações que surge o discurso ideológico que coloca a educação como uma espécie de "galinha dos ovos de ouro" (FrigotTo, 1996).

As intervenções nacionais e locais nos anos 90 no campo educativo possuem, em boa medida, como marco, a Conferência Mundial sobre Educação para Todos, realizada em Jomtien na Tailândia. A conferência foi convocada pela Organização das Nações Unidas para a Educação, a Ciência e a Cultura (Unesco), pelo Fundo das Nações Unidas para a Infância (Unicef), pelo Programa das Nações Unidas para o Desenvolvimento (Pnud), e pelo Banco Mundial, trazendo um viés de educação voltada para a eqüidade social - como se fosse possível solucionar o problema da desigualdade entre classes sociais com intervenções pontuais. É dentro desse contexto geral que deve ser compreendida a iniciativa do governo de Goiás em instituir um projeto que possa garantir aos educandos, com distorção entre idade e série, a passagem exitosa pelo ensino fundamental.

Portanto, tendo feito esses apontamentos preliminares, quero desfazer uma possível impressão logo de início: a de que a iniciativa do governo de Goiás é negativa. Penso que, diante de uma necessidade prática, faz-se necessário uma intervenção; contudo, a forma, a dimensão e o conteúdo da intervenção é que merecem ser objeto de análise crítica. Esta é a intenção do presente estudo.

\section{A ESPECIFICIDADE DA FORMAÇÃO PROFISSIONAL NO MAGISTÉRIO E A EDUCAÇÃO FÍSICA}

A cada dia torna-se mais claro o fato de a formação profissional para o magistério não poder circunscrever-se a uma mera transmissão ou atualização de conhecimentos. É cada vez mais evidente que o racionalismo técnico não consegue satisfazer as necessidades da formação para a docência em uma sociedade como a nossa.

Analisando as diferentes concepções que orientam o processo de formação de professores, pode-se perceber que elas se associam a modelos que tendem para avanços ou recuos. Nesse sentido, os estudos de Porto (2000) mostram-nos que as concepções de formação podem, 
de forma geral, ser agrupadas em duas grandes tendências: a "estruturante", marcada pelo viés tradicional, que define antecipadamente os programas, procedimentos e recursos a serem aplicados aos grupos de professores; e a "interativo-construtivista", pautada pela dialética e pela reflexão investigativa crítica, organizada a partir de contextos particulares e das necessidades concretas dos professores.

De acordo com Imbernón (2000), durante muito tempo, a formação para o magistério baseou-se em conhecimentos que poderíamos denominar de "conteúdos", e a perspectiva técnica e racionalista que orientava a formação dava o norte a ser seguido. Sua expressão mais clara era a preferência pelo metodológico, e seu horizonte era a formação de um profissional com o domínio uniforme do conhecimento científico e psicopedagógico. É que antigamente dominar um certo conteúdo formal era assumir a capacidade de ensiná-lo, ao passo que, hoje, vê-se que isso não cabe mais.

Ora, quando enfocamos a docência, vemos que o professor não é um técnico a executar seu ofício e muito menos um funcionário a cumprir instruções vindas de fora. É difícil generalizar situações de docência. É nesse sentido que o profissional docente deve aprender a investigar sua própria prática e as situações contextualizadas com que se defronta.

Trata-se de formar um professor como um profissional práticoreflexivo que se defronta com situações de incerteza, contextualizadas e únicas, que recorre a investigação como uma forma de decidir e de intervir praticamente em tais situações.

O processo de formação deve dotar os professores de conhecimentos, habilidades e atitudes para desenvolver profissionais reflexivos ou investigadores. Nesta linha, o eixo fundamental do currículo de formação do professor é o desenvolvimento da capacidade de refletir sobre a própria prática docente, com o objetivo de aprender a interpretar, compreender e refletir sobre a realidade social e a docência. (IMBERnón, 2000, p. 39)

Diante de tal perspectiva, como se situa a questão da formação de professores de educação física? Sobre isso cabe afirmar categoricamente que a formação desse profissional não destoa em 
nada da concepção de formação aludida anteriormente. O motivo é que o professor de educação física também é um educador, e sua área de conhecimento situa-se no campo da educação, ou seja, no campo da formação humana. Contudo, a área tem sua própria história e isso lhe confere aspectos que precisam ser levados em consideração. ${ }^{5}$

Em relação à educação física em Goiás duas são as instituições de maior tradição na formação de professores: a Escola Superior de Educação Física e Fisioterapia do Estado de Goiás (Eseffego-UEG) e a Faculdade de Educação Física da Universidade Federal de Goiás (FEF-UFG). A primeira, fundada em 1962, foi durante décadas marcada pela perspectiva tecnicista, freada com as reformas curriculares da década de 1990. A segunda foi criada em 1987, no bojo de uma proposta avançada, vinculada à Faculdade de Educação. Atualmente, ambas as faculdades procuram construir o processo de formação profissional dentro de uma perspectiva crítica de educação física, entendendo-a como a disciplina que na escola tratará da cultura corporal do homem e da mulher brasileira. ${ }^{6}$ É possível dizer que essa é a orientação não única, mas a mais significativa, no que tange à formação de professores de educação física em Goiás, ${ }^{7}$ e que esses profissionais, formados dentro dessa perspectiva, provavelmente têmse integrado às redes municipal e estadual de ensino nos últimos concursos públicos.

\section{O PROJETO EM QUESTÃO: ACELERANDO PARA FRENTE OU PARA TRÁS?}

A questão da defasagem escolar é de fato um problema sério em Goiás. Segundo dados que constam no próprio projeto do programa de aceleração, a taxa de distorção entre série e idade, em relação ao ensino fundamental em Goiás, é de 62,2\% nas 5aㅗ séries e 62,7\% nas $6^{\mathrm{a}}$ séries. Diante de tão dramática realidade e da atual conjuntura em que se situa a educação, o governo de Goiás buscou uma estratégia de intervenção, elaborando um meio para corrigir a defasagem dos alunos. Por isso, a Secretaria Estadual de Educação (SEE) construiu um projeto com data de fevereiro de 2001 e aprovado pelo Conselho 
Estadual de Educação em 11 de setembro de 2001. Para a concretização do projeto, buscou-se a assessoria do Centro de Estudos e Pesquisa em Educação, Cultura e Ação Comunitária (Cenpec).

Para que os professores pudessem desenvolver satisfatoriamente o projeto, foi realizada a sua preparação através de cursos de capacitação. Analisando o projeto, fica evidente inclusive uma preocupação maior do que aquela que se refere à capacitação dos professores para a atuação na proposta a ser desenvolvida: a preocupação com a formação continuada. Tal perspectiva é explicitada quando vê-se que a proposta

Possui um caráter formativo, devendo estar estreitamente vinculada a um plano de formação continuada dos professores, que lhes permita apropriarem-se de sua concepção construtiva.

As atividades propostas e as respectivas orientações ao professor visam instalar uma dinâmica na sala de aula que favoreça as interações, estimule a participação e o debate, mobilize interesses, promova busca de informações, a organização e o hábito de registro. (Secretaria Estadual de Educação, 2001, p. 18)

Para a realização das referidas capacitações, a SEE, como consta no projeto, organizou cinco capacitações assessoradas pelo Cenpec para os professores da rede no ano de 2001, com previsão de continuidade no ano seguinte. Nesse contexto, cabe o seguinte questionamento: qual foi a concepção de formação docente instituída no referido projeto? Para responder a essa pergunta serão tecidas considerações sobre o modelo geral da capacitação dos professores e o recurso metodológico utilizado.

O modelo geral de capacitação de professores do projeto de aceleração de aprendizagem para alunos de $5^{\mathrm{a}}$ e $6^{\mathrm{a}}$ séries baseou-se na idéia do professor multiplicador, ou seja, um professor especialista na área, especialmente designado pela SEE, faz o curso de capacitação promovido pelo Cenpec e, quando retorna, retransmite os repasses aos professores de sua respectiva área nos cursos de capacitação para os professores da rede vinculados ao programa. Tal perspectiva de trabalho encontra sérios limites pelo fato de 
fragmentar o conhecimento, empreendendo uma visão parcelar justamente para os docentes que, em sua prática pedagógica cotidiana, precisam do entendimento ampliado das questões educativas.

Em relação ao recurso metodológico utilizado, nota-se visivelmente um viés conservador manifestado em uma proposta organizada em sentido vertical. Os professores encontraram tudo pronto - era só consumir, até mesmo as aulas. Os modelos de aula vinham com o tema, alvos, o que fazer, como fazer e avaliar, cabendo ao professor a tarefa de executar aquilo que foi prescrito pelos especialistas externos à escola.

Um horizonte de formação continuada dessa natureza dificilmente pode resultar em avanço qualitativo da prática pedagógica, como bem nos mostra as palavras de Alarcão (1998, p. 115-116):

Qualquer formação que ignore a experiência e a realidade profissional do professor apresenta-se desprovida de sentido, quase insultosa, pelo que oportunidades de refletir sistematicamente sobre sua própria ação profissional, de se autoconhecer nas suas potencialidades e nos seus limites, de se formar em colaboração com os outros professores, seus colegas, são estratégias de formação a desenvolver.

Entre os aspectos que envolvem o projeto, vale mencionar que, segundo sua proposta, ele será vinculado ao projeto pedagógico da escola:

Esse não é um trabalho isolado, fora do contexto escolar, mas é parte inerente do Projeto Pedagógico da escola e como tal deverá ser assumido, discutido com a comunidade, tornando-se consenso de todos os envolvidos no processo (SECRETARIA EsTADUAL DE EDUCAÇÃo, 2001, p. 8).

Nota-se claramente que essa intenção não ultrapassa o plano das palavras e que, na realidade, isso seria mesmo impossível, pois a concepção de intervenção pedagógica expressa no projeto de aceleração de aprendizagem faz um movimento de fora para dentro em relação à escola, enquanto o projeto político-pedagógico faz o movimento inverso, ou seja, de dentro para fora. 
Isto posto, vamos a uma outra questão séria e que conferiu limites à proposta do projeto: o fato de não se ter respeitado o eixo teórico em que são formados os professores de educação física em Goiás, trazendo de forma autoritária - e não é outra palavra que pode expressar melhor a unilateralidade das decisões - uma outra concepção para essa disciplina.

Verificando o texto de apoio à capacitação de professores do Cenpec, nota-se qual importância da educação física escolar dentro da perspectiva trazida:

A Educação Física Escolar é uma disciplina muito importante e necessária, sobretudo nos dias de hoje, quando o extraordinário avanço científico e tecnológico, empregado numa dinâmica capitalista, torna o ser humano cada vez mais sedentário. (CENPEC. Educação física: concepção da área)

Não é verdade que a importância da educação física escolar tenha sua justificativa assinalada devido ao aumento dos casos de sedentarismo. Sua importância, como nos informa Castellani Filho (1998), relaciona-se ao fato de ser a disciplina que, no interior da escola, tratará dos temas da cultura corporal - jogo, dança, luta, ginástica, esportes etc. -, propiciando aos alunos a sua apropriação, ou seja, a constatação, a demonstração, a compreensão e a explicação dessa dimensão humana.

O texto do Cenpec delinea uma concepção de educação física que avança no sentido de propor a reflexão sobre o movimento humano. Contudo, vejamos a qual movimento humano refere-se:

Cabe esclarecermos, entretanto, que entendemos por movimento toda e qualquer alteração de um ou mais segmentos corporais num padrão espaço-temporal, desenvolvido através de contrações musculares, sendo prioritário a utilização de energia.

Vale ressaltar que a Cinesiologia é a grande área mãe de estudos do movimento humano, cabendo à Educação Física o estudo do movimento humano aplicado pedagogicamente nas mais diferentes situações de ensino formais e não formais. (CENPEC. Educação física: concepção da área) 
Ora, a perspectiva de movimento humano trazida pelo Cenpec não permite que se veja a especificidade da educação física, apresentando-a como um conceito amorfo. $\mathrm{O}$ que qualifica a sua especificidade, como mostra Bracht (1992), é o movimento humano com sentido e significado em um contexto histórico-social. Portanto, não é qualquer movimento que pode se inscrever no horizonte da educação física.

O Cenpec procura situar sua concepção como "movimento humano consciente". Entretanto, ao realizar a seleção prévia dos conteúdos, indica que isso se dará a partir da apreensão de conhecimentos acerca do aparelho locomotor, respiratório e cardiovascular, capacidades físicas e psicomotoras (CENPEC. "Somos estruturados para nos mover" - texto de apoio). Tal fato inverte o sentido da educação física escolar, pois, concordando com Taffarel et al. (1993), entendo que os conteúdos descritos anteriormente não são os da educação física e sim aqueles que o professor precisa saber para ensinar educação física, afinal, os conteúdos e temas dessa disciplina situam-se no âmbito da cultura corporal.

Dessa forma, o que se pode perceber na concepção de educação física do Cenpec é que ela não é congruente com a concepção orientadora das mais significativas instituições de formação de professores de educação física em Goiás: a Eseffego-UEG e a FEFUFG. Essas instituições orientam seus cursos no eixo da perspectiva da cultura corporal e da teoria crítica da educação. Portanto, fica claro o desrespeito ao saber dos professores da rede estadual ao desconsiderar essa característica das instituições formadoras em Goiás.

\section{INSINUANDO OUTRO CAMINHO}

Pelo que se pode observar no decorrer deste artigo, a proposta de formação de professores expressa no projeto de aceleração de aprendizagem de 5a e $6^{a}$ séries em Goiás, especificamente no que se refere à educação física, encontra sérias contradições. Isso fica patente quando se verifica que o projeto foi concebido com o intuito de formar quadros para o programa e oferecer formação continuada, 
porém, sem atentar para a especificidade do trabalho docente e sem respeitar os saberes dos professores.

A proposta de formação docente do projeto aparentemente emerge como sendo das mais arrojadas. Todavia, pela sua análise, manifesta-se como conservadora, aliando-se às demais propostas de formação de professores da rede estadual de ensino. ${ }^{8}$ Se a intenção é modificar verdadeiramente a prática pedagógica, não basta que se mudem os óculos, mas o olhar dos professores. Esse não será nunca um caminho fácil, mas é sem dúvida um caminho possível.

Acredito que uma proposta viável possa ser construída respeitando-se cinco pontos essenciais:

- respeito ao saber docente, ou seja, reconhecimento de que o professor possui conhecimentos que devem ser valorizados;

- adoção, como palco privilegiado para a formação continuada, do próprio contexto escolar em que o professor trabalha;

- elaboração de processos de reflexão individual e coletiva;

- construção de projetos coletivos orientados pela perspectiva da pesquisa-ação, o que favorece que o professor seja pesquisador de sua própria prática;

- estruturação de condições concretas para o trabalho pedagógico na escola.

Dessa forma, seria possível o encaminhamento de uma iniciativa de formação continuada mais próxima à escola e menos prescritiva. O que é preciso ter claro é que a prática educativa deve inscrever-se em um outro patamar qualitativo e que a formação para a docência não cabe mais em pacotes fechados.

Por último, chamo atenção para algo que permanece velado em uma proposta como esta e que foi objeto de análise, que é a questão das mais relevantes, pois se refere a outra ponta da corrente, ou seja, o aluno. Entendo que um projeto como o de aceleração da aprendizagem pode ser alimentado ad infinitum por alunos oriundos do fluxo regular do ensino fundamental se a escola que temos não avançar. Se intervir em relação aos alunos que estão com defasagem entre série e idade é importante, também importante é concentrar 
esforços para melhorar a qualidade do fluxo regular do ensino fundamental e médio. Em face disto, o Estado não pode omitir-se, pois o preço a ser pago - notadamente pelo aluno - pode ser o de uma eterna aceleração.

\section{ABSTRACT}

The aim of this article is to analyse the perspective of teaching formation for teachers pertaining to the Project of Learning Acceleration in Goiás, focusing especially physical education teachers. This study was done by documental analysis, regarding to the project of learning acceleration itself, as well as by theorical reflection on the authors that discuss about teaching formation. The analysis of this issue allowed us to verify a perspective in teaching formation strongly influenced by technical reasoning and depreciation of teacher's knowledge, also revealing a conception of Physical Education much different from the one that has been developed by the Institutions of Higher Teaching in Goiás.

Key-words: physical education, continued formation, elementary teaching, learning acceleration.

\section{NOTAS}

3. É importante ter claro que essa mudança no tipo de formação requerida não é homogênea, ou seja, não implica em dissolução das outras formas de preparação para o trabalho. Afinal, como mostra Oliveira (2000), nos países latino-americanos coexistem diferentes modelos de exploração do trabalho, o que implica em níveis diferenciados de formação do trabalhador.

4. Não se é contra o avanço tecnológico. A questão central é que a tecnologia deve ser posta em benefício das necessidades humanas e não de monopólios privados.

5. A respeito do processo histórico da educação física no Brasil, ler Castellani Filho (1994) e Soares (1994).

6. Não é objetivo deste trabalho discutir as questões teórico-metodológicas que permeiam o campo da educação física. A esse respeito pode-se consultar Castellani Filho (1998), em que o autor aborda aquilo que domina de concepções propositivas e não-propositivas para a área. 
7. A pesquisa empreendida por Moura (2001) mostrou claramente que as concepções dentro de uma instituição não são monolíticas, podendo ser compreendidas como uma relação de hegemonia.

8. A rede estadual tem disponibilizado como formação continuada a seus professores, além dos cursos superiores da licenciatura parcelada da UEG - iniciativa que merece reconhecimento -, diversas oportunidades de formação a seus professores, porém é preciso notar a perspectiva pragmatista que tem marcado esses cursos de formação. Cursos como os de capacitação para professores do ensino médio, conservação dos prédios escolares, TV-escola, pró-gestão e paz na escola são alguns exemplos.

\section{REFERÊNCIAS}

ALARCÃO, I. Formação continuada como instrumento de profissionalização docente. In: VEIGA, I. P. A. (Org.). Caminhos da profissionalização do magistério. Campinas: Papirus, 1998.

BRACHT, V. Educação física e aprendizagem social. Porto Alegre: Magister, 1992.

CASTELLANI FILHO, L. Educação física no Brasil: a história que não se conta. 4. ed. Campinas: Papirus, 1994.

- Política educacional e educação física. Campinas: Autores Associados, 1998.

CENPEC. Educação física: concepção da área - texto de apoio à capacitação de professores, s.d. (Mimeo).

CENPEC. Educação física: somos estruturados para nos mover - texto de apoio à capacitação de professores, s.d. (Mimeo).

FRIGOTTO, G. A ideologia que embala a galinha dos ovos de ouro. In: GUIMARÃES, G. (Org.). Sindicalismo \& cooperativismo: a economia solidária em debate. São Paulo: Unitrabalho, s.d.

GOIÁS. Secretaria Estadual de Educação. Projeto de aceleração da aprendizagem de 5a e 6 ${ }^{\underline{a}}$ séries. Goiânia, 2001.

IMBERNÓN, F. Formação docente e profissional: formar-se para a mudança e a incerteza. São Paulo: Cortez, 2000.

MOURA, S. A. Formação de professores de educação física da FEF/UFG: um olhar de limites e possibilidades. Goiânia, 2001. Dissertação (Mestrado 
em Educação Física) - Faculdade de Educação, Universidade Federal de Goiás.

OLIVEIRA, Dalila, A. Educação básica: gestão do trabalho e da pobreza. Petrópolis: Vozes, 2000.

PORTO, Y. S. Formação continuada: a prática pedagógica recorrente. In: MARIN, A. J. Educação continuada. Campinas: Papirus, 2000.

SOARES, C. L. Educação física: raízes européis e Brasil. Campinas: Autores Associados, 1994.

TAFFAREL, C. N. Z. et al. A educação física escolar na perspectiva para o século XXI. In: MOREIRA, W. W. (Org.). Educação física \& esportes: perspectivas para o século XXI. Campinas: Papirus, 1993. 